\title{
Fibroblast growth factor 2 suppresses the expression of C-C motif chemokine 11 through the c-Jun N-terminal kinase pathway in human dental pulp-derived mesenchymal stem cells
}

\author{
RIKA KUROGOUSHI $^{1,2}$, TOMOKAZU HASEGAWA ${ }^{1}$, YUKI AKAZAWA ${ }^{1}$, KOKORO IWATA $^{2}$, ASUNA SUGIMOTO $^{2}$, \\ KIMIKO YAMAGUCHI-UEDA ${ }^{1}$, AYA MIYAZAKI ${ }^{1}$, ANRIZANDY NARWIDINA ${ }^{1}$, KEITA KAWARABAYASHI ${ }^{1}$, \\ TAKAMASA KITAMURA ${ }^{1}$, HIROSHI NAKAGAWA ${ }^{1}$, TOMONORI IWASAKI ${ }^{1}$ and TSUTOMU IWAMOTO $^{2}$ \\ ${ }^{1}$ Department of Pediatric Dentistry, Institute of Biomedical Sciences, Tokushima University Graduate School, \\ Kuramoto, Tokushima 770-8504; ${ }^{2}$ Department of Pediatric Dentistry/Special Needs Dentistry, \\ Division of Oral Health Sciences, Graduate School of Medical and Dental Sciences, \\ Tokyo Medical and Dental University, Tokyo 113-8549, Japan
}

Received July 2, 2021; Accepted September 7, 2021

DOI: $10.3892 / \mathrm{etm} .2021 .10791$

\begin{abstract}
The regulation of the mesenchymal stem cell (MSC) programming mechanism promises great success in regenerative medicine. Tissue regeneration has been associated not only with the differentiation of MSCs, but also with the microenvironment of the stem cell niche that involves various cytokines and immune cells in the tissue regeneration site. In the present study, fibroblast growth factor 2 (FGF2), the principal growth factor for tooth development, dental pulp homeostasis and dentin repair, was reported to affect the expression of cytokines in human dental pulp-derived MSCs. FGF2 significantly inhibited the expression of chemokine C-C motif ligand 11 (CCL11) in a time- and dose-dependent manner in the SDP11 human dental pulp-derived MSC line. This inhibition was diminished following treatment with the AZD4547 FGF receptor (FGFR) inhibitor, indicating that FGF2 negatively regulated the expression of CCL11 in SDP11 cells. Furthermore, FGF2 activated the phosphorylation of p38 mitogen-activated protein kinase (p38 MAPK), extracellular signal-regulated kinase 1/2 (ERK1/2) and c-Jun $\mathrm{N}$-terminal kinases (JNK) in SDP11 cells. The mechanism of the FGFR-downstream signaling pathway was then studied using the SB203580, U0126 and SP600125 inhibitors for p38 MAPK, ERK1/2, and JNK, respectively. Interestingly,
\end{abstract}

Correspondence to: Professor Tsutomu Iwamoto, Department of Pediatric Dentistry/Special Needs Dentistry, Division of Oral Health Sciences, Graduate School of Medical and Dental Sciences, Tokyo Medical and Dental University, 1-5-45 Yushima, Bunkyo-ku, Tokyo 113-8549, Japan

E-mail: iwamoto.dohs@tmd.ac.jp

Key words: dental pulp-derived mesenchymal stem cells, fibroblast growth factor 2, fibroblast growth factor receptor signal, $\mathrm{C}-\mathrm{C}$ motif ligand 11, c-Jun $\mathrm{N}$-terminal kinase only treatment with SP600125 blocked the FGF2-mediated suppression of CCL11. The present results suggested that FGF2 regulated the expression of cytokines and suppressed the expression of CCL11 via the JNK signaling pathway in human dental pulp-derived MSCs. The present findings could provide important insights into the association of FGF2 and CCL11 in dental tissue regeneration therapy.

\section{Introduction}

Tissue-specific mesenchymal stem cells (MSCs) play an important role in tissue regeneration and homeostasis; they have been isolated from various body tissues, such as bone marrow (1), skeletal muscle (2), skin (3), adipose (4), umbilical cord blood (5), dental pulp (6) and periodontium (7). In particular, due to their less invasive collection method compared with other tissue sources, tooth-derived MSCs are expected to be a promising stem cell source $(7,8)$. However, tissue regeneration involves not only the differentiation of MSCs into tissue-specific cells but also the development of the microenvironment for the stem cell niche, which is composed of various cytokines and immune cells (9). The combination of optimal MSC scaffolds with various cytokines that promote cell migration and differentiation is an important strategy in tissue regenerative medicine $(10,11)$. In addition, tissue regeneration is known to depend on the inflammatory response $(12,13)$. Interestingly, a number of studies have reported the accumulation of MSCs in the early stages of inflammation in damaged tissues with chronic inflammation $(12,13)$, suggesting that the association between MSCs and immune response is important during the regeneration process.

Fibroblast growth factor 2 (FGF2) is a heparin-binding protein that is expressed in a wide range of cells and tissues, functioning as a pluripotent growth factor and serving an important role in many physiological and pathological processes, including limb development, neurogenesis, angiogenesis, wound healing and tumor growth $(14,15)$. One of the properties of FGF2 is the regulation of proliferation in 
various stem cells, such as embryonic stem cells and MSCs, indicating that FGF2 plays crucial roles in embryogenesis and tissue regeneration. Interestingly, FGF2-deficient mice were viable, fertile and phenotypically indistinguishable from homozygous FGF2 wild-type littermates upon gross examination (16). However, FGF2-deficient mice were characterized by a decrease in neuronal density in the frontal motor cortex, modestly delayed skin wound healing and decreased bone mass and new bone formation $(16,17)$. These results indicated that FGF2 played a key role in neurogenesis, wound healing and bone formation. Therefore, FGF2 was assumed to act as a tissue regeneration factor in bone defects associated with periodontal disease. Furthermore, FGF2 has also been studied as a therapeutic agent for diseases such as traumatic skin wounds (18). Thus, FGF2 is likely to play a central role in tissue regeneration.

Chemokine C-C motif ligand 11 (CCL11), also known as eotaxin, is an eosinophil-specific chemoattractant cytokine that plays an important role in inflammatory and allergic conditions such as asthma and eosinophilia (19). Chemokine C-C motif receptor 3 (CCR3), which acts as a receptor for CCL11 and is involved in allergic inflammation, is highly expressed in eosinophils, basophils and type 2 helper lymphocytes (20). In addition, CCL11 has also been reported to bind C-C chemokine receptor type 2 (CCR2) and CCR5; however, it functions as an antagonist and agonist, respectively, indicating that CCL11 plays an ambivalent role in the fine-tuning of cellular responses at inflammation sites (21). Furthermore, CCL11 was also reported to increase in animal plasma and cerebrospinal fluid samples with age, correlating with a decrease in neurogenesis in heterochronic parabiosis and aged mice (22). Recently, increased levels of CCL11 were found to be correlated with telomere length (23). Thus, CCL11 was assumed to be an aging factor with a specific role in the negative regulation of neurogenesis (24). In addition, circulating levels of CCL11 are used in clinical studies as a biomarker of gastric cancer and postmenopausal osteoporosis (25). A PABP-interacting motif 2-induced inflammation mouse model indicated that osteoblasts expressed CCL11, whereas osteoclasts expressed the CCL11-high affinity receptor CCR3, with CCL11 promoting the migration of osteoclast precursors (26). These observations indicated that the CCL11/CCR3 axis is also involved in pathological bone metabolism.

The present study aimed to characterize the changes in cytokine and chemokine expression induced by FGF2 in human dental pulp-derived MSCs.

\section{Materials and methods}

Reagents.FGF2 and AZD4547(FGFR inhibitor) were purchased from R\&D Systems, Inc. and Santa Cruz Biotechnology, Inc., respectively. SB203580 (p38 MAPK inhibitor) and SP600125 (JNK inhibitor) were purchased from FUJIFILM Wako Pure Chemical Corporation. U0126 [MAPK kinase (MEK) inhibitor], anti-ERK1/2 (cat. no. \#9102), anti-phosphorylated (p)-ERK1/2 (cat. no. \#9101), anti-p38 MAPK (cat. no. \#8690), anti-p-p38 MAPK (cat. no. \#9211), anti-stress-activated protein kinases (SAPK)/JNK (cat. no. \#9252), anti-p-SAPK/JNK (cat. no. \#4668) and anti- $\beta$-actin antibodies (cat. no. \#4967) were purchased from Cell Signaling Technology, Inc.
Cells. SDP11 cells were used in the present study. We previously established the cell line, SDP11, from the dental pulp tissues of human deciduous teeth that were obtained from 3 healthy children aged between $6-8$ years old $(27,28)$. Informed consent was obtained from the donors' parents, following the guidelines of Tokushima University Hospital (Tokushima, Tokyo, Japan) prior to tooth extraction during orthodontic treatment. The present study protocol was approved by the University of Tokushima Hospital Ethical Review Committee (approval no. 1799). The tissues sections were chopped into pulp using a surgical blade and digested with collagenase $\left(2 \mathrm{mg} / \mathrm{ml}\right.$ ) at $37^{\circ} \mathrm{C}$ for $30 \mathrm{~min}$. After being washed with PBS (Sigma-Aldrich; Merck KGaA), the tissues were placed on a cell culture dish and maintained in $\alpha$-modified minimum essential medium ( $\alpha$-MEM; Gibco; Thermo Fisher Scientific, Inc.) supplemented with 10\% FBS (Gibco; Thermo Fisher Scientific, Inc.). Migrated fibroblastic cells were used as dental pulp cells (DPCs). DPCs were transfected with the pBABE-neo-hTERT plasmid (Addgene, Inc.) using Lipofectamine $^{\text {TM }}$ LTX (Invitrogen; Thermo Fisher Scientific, Inc.) according to the manufacturer's protocol. The transfected cells were maintained $24 \mathrm{~h}$ after transfection using the selective antibiotic G418 (Gibco; Thermo Fisher Scientific, Inc.) at a concentration of $200 \mu \mathrm{g} / \mathrm{ml}$ for 12-15 days. Then, single-cell clones were obtained by the limiting dilution cloning method. Clones generated by single-cell clones were named single-cell clone derived from human deciduous tooth pulp cells (SDP). SDP11 was derived from clone number 11.

Cell culture. SDP11 cells were cultured in $\alpha$-MEM supplemented with 10\% FBS and 5\% antibiotic-antimycotic (penicillin G, streptomycin sulfate and amphotericin B) mixture (Gibco; Thermo Fisher Scientific, Inc.). All cultures were maintained at $37^{\circ} \mathrm{C}$ in a humidified atmosphere containing $5 \% \mathrm{CO}_{2}$.

Comprehensive expression profiling and quantitative reverse transcription-quantitative PCR (RT-qPCR). SDP11 cells were plated at $6.0 \times 10^{4}$ cells $/ \mathrm{cm}^{2}$ in a $35-\mathrm{mm}$ culture dish and reached $100 \%$ confluence after $24 \mathrm{~h}$. Then, cells were treated with $20 \mathrm{ng} / \mathrm{ml} \mathrm{FGF2}$ for $48 \mathrm{~h}$ for comprehensive expression profiling and for $6,12,24,48$ and $72 \mathrm{~h}$ for CCL11 expression. To test the effect of FGF2 concentration on the expression of CCL11, SDP11 cells were cultured with 0.1, 1, 10, 20 and $40 \mathrm{ng} / \mathrm{ml} \mathrm{FGF2}$ for $24 \mathrm{~h}$. To examine the effect of AZD4547, SB203580, U0126 or SP600125, SDP11 cells were cultured in the presence or absence of $20 \mathrm{ng} / \mathrm{ml} \mathrm{FGF2}$ and with or without $10 \mu \mathrm{M}$ inhibitor for $24 \mathrm{~h}$. Total RNA was extracted from pretreated SDP11 cells using TRIzol ${ }^{\circledR}$ reagent (Invitrogen; Thermo Fisher Scientific, Inc.) according to the manufacturer's instructions. A total of $2 \mu \mathrm{g}$ extracted total RNA was used to produce first-strand cDNA using the PrimeScript ${ }^{\mathrm{TM}}$ RT Master Mix (Perfect Real Time; Takara Bio, Inc.) in accordance with the manufacturer's instructions. qPCRwas performed using TB Green ${ }^{\mathrm{TM}}$ Premix Ex Taq ${ }^{\mathrm{TM}}$ II (Takara Bio, Inc.), according to the manufacturer's instructions, and the Thermal Cycler Dice Real Time system (Takara Bio, Inc.) under the following conditions: $95^{\circ} \mathrm{C}$ for $5 \mathrm{sec}$, followed by 45 cycles of $95^{\circ} \mathrm{C}$ for $5 \mathrm{sec}, 62^{\circ} \mathrm{C}$ for $30 \mathrm{sec}$ and $72^{\circ} \mathrm{C}$ for $20 \mathrm{sec}$, with a final cycle at $95^{\circ} \mathrm{C}$ for $15 \mathrm{sec}, 62^{\circ} \mathrm{C}$ for $30 \mathrm{sec}$ and $95^{\circ} \mathrm{C}$ for $15 \mathrm{sec}$. 
Table I. Gene list in the PrimerArray ${ }^{\circledR}$ of human cytokine-cytokine receptor interactions.

Category Gene name

Cytokine genes

IL2RG, KIT, MET, IFNGR1, IL1A, IL8, IL6, CXCL12, IL10RB, IL8RA, TGFB1, CSF1, CSF3R, IL2RB, KITLG, PRLR, LEPR, HGF, TGFBR2, VEGFA, TNFRSF1A, ACVR1, ACVR2B, BMPR1B, BMPR2, CCR1, CX3CR1, IL13RA1, IL18, CXCL10, CCR7, CNTFR, EGF, FLT4, CXCL2, IL1RAP, IL7R, IL13, INHBA, INHBB, KDR, LTBR, CXCL9, NGFR, TNFRSF11B, PDGFB, CCL2, CCL5, CCL11, CCL18, CCL21, CCL22, CCL24, CXCL5, CX3CL1, TGFB2, TGFB3, VEGFB, TNFSF12, TNFSF10, TNFRSF10D, TNFRSF10B, TNFRSF10A, OSMR, FLT3, ACVR1B, BMPR1A, CCR6, CCL20, TGFBR1, CXCL14, CSF1R, CCL13, PDGFRA, CXCR6, IL17RA, IL20RA, PDGFC, TNFRSF12A, EDA2R, CXCL16, PLEKHQ1, TSLP, CCL28, CD40, IL28RA, IL6ST, EGFR

Housekeeping genes

GUSB, HPRT1, PGK1, ACTB, GAPDH, TBP, B2M, PPIA

Regarding primer information, comprehensive gene expression profiling was performed using the PrimerArray ${ }^{\circledR}$ (human cytokine-cytokine receptor interactions, cat. no. PH001; Takara Bio, Inc.) that was packaged into premixed 96 primer pairs (Table I) in a single-use 96-well plate. The primer sequences used for CCL11 and GAPDH were as follows: CCL11 forward, 5'-CTTCAGCCTCCAACATGAAGGTC-3' and reverse, 5'-CTATTGGCCAGGTTAAAGCAGCA-3'; GAPDH forward, 5'-GCACCGTCAAGGCTGAGAAC-3' and reverse, 5'-TGGTGAAGACGCCAGTGG-3'. The predicted size of each fragment was 130 and 267 base pairs, respectively. CCL11 expression was corrected using the housekeeping gene GAPDH. Relative gene expression was analyzed using the $2^{-\Delta \Delta c q}$ method (29).

Western blotting. SDP11 cells were plated at a density of $3.0 \times 10^{4}$ cells $/ \mathrm{cm}^{2}$ in a $60-\mathrm{mm}$ culture dish, in which cells reached a confluence of $80 \%$ after $24 \mathrm{~h}$. Prior to FGF2 treatment, the culture dish was washed thrice with PBS, replaced with serum-free $\alpha$-MEM and incubated at $37^{\circ} \mathrm{C}$ for $1 \mathrm{~h}$. Cells were then incubated with or without $20 \mathrm{ng} / \mathrm{ml} \mathrm{FGF2}$ and in the presence or absence of $10 \mu \mathrm{M}$ SB203580, U0126 or SP600125 for $5 \mathrm{~min}$. After these treatments, SDP11 cells were washed thrice with PBS containing $1 \mathrm{mM}$ sodium vanadate $\mathrm{Na}_{3} \mathrm{VO}_{4}$ (Sigma-Aldrich; Merck KGaA) and lysed in $100 \mu$ l Cellytic M reagent solution buffer (Sigma-Aldrich; Merck KGaA) supplemented with complete mini protease inhibitor cocktail tablets (Roche Diagnostics) and PhosSTOP ${ }^{\text {тм }}$ (Roche Diagnostics). Lysed cells were collected and centrifuged at 13,205 $\mathrm{x}$ g for 5 min at $4^{\circ} \mathrm{C}$. Protein concentration was measured using the micro-BCA protein assay reagent (Pierce; Thermo Fisher Scientific, Inc.), according to the manufacturer's instructions. Subsequently, $10 \mu \mathrm{g}$ of lysate protein denatured in LDS sample buffer (Invitrogen; Thermo Fisher Scientific, Inc.) containing a NuPAGE ${ }^{\mathrm{TM}}$ Sample Reducing Agent (Invitrogen; Thermo Fisher Scientific, Inc.) was loaded onto each well of NuPAGE $^{\mathrm{TM}}$ 4-12\% Bis-Tris Protein gels (Invitrogen; Thermo Fisher Scientific, Inc.). After loading onto the NuPAGE 4-12\% Bis-Tris Protein gels, proteins were transferred to PVDF membranes (Invitrogen; Thermo Fisher Scientific, Inc.) and blocked with 5\% skimmed milk in Tris-buffered saline containing $0.05 \%$ Tween-20 (Bio-Rad Laboratories,
Inc.) for $40 \mathrm{~min}$ at room temperature. Membranes were then immunoblotted for $40 \mathrm{~min}$ at room temperature with primary antibodies (anti-ERK1/2, anti-p-ERK1/2, anti-p38 MAPK, anti-p-p38 MAPK, anti-SAPK/JNK, anti-p-SAPK/JNK and anti- $\beta$-actin; all, 1:1,000). Membranes were subsequently incubated for $40 \mathrm{~min}$ at room temperature with the HRP-conjugated anti-rabbit IgG secondary antibody (Cell Signaling Technology, Inc.; \#7074; 1:1,000). Membranes were visualized using an ECL kit (Cytiva), according to the manufacturer's instructions. Blot images were acquired using an Amersham ${ }^{\mathrm{TM}}$ Imager 600 (Cytiva).

Statistical analysis. Each experiment was run in triplicate. For the analyses presented in Figs. 2, 3, 4 and 5D, data were pooled from three independent experiments, and the results were presented as the mean \pm standard error of the mean. In Fig. 5A-C, the data from three independent experiments with similar results are shown as representatives. Error bars indicate standard deviations. Statistical analysis was performed with one-way ANOVA and Tukey post hoc test using MS Excel (version 16.52; Microsoft Corporation). $\mathrm{P}<0.05$ was considered to indicate a statistically significant difference.

\section{Results}

Altered expression of cytokines in FGF2-treated cells. To clarify the interactions between FGF2 and the immune system in dental pulp-derived MSCs, the expression of cytokines in FGF2-treated SDP11 cells was examined using a PrimerArray ${ }^{\circledR}$ consisting of human cytokine-cytokine receptor interactions (Table I). The cells were treated with $20 \mathrm{ng} / \mathrm{ml} \mathrm{FGF2}$ for $48 \mathrm{~h}$, after which gene expression was assessed by RT-qPCR using the PrimerArray ${ }^{\circledR}$ as aforementioned. A total of 48 molecules involved in the immune response were found to be expressed in SDP11 cells and, interestingly, FGF2 suppressed the expression of chemokine $\mathrm{C}-\mathrm{C}$ motif ligand 11 (CCL11) among expressed cytokines (Fig. 1). No satisfactory amplification products were found in 40 cytokine genes.

FGF2-induced suppression of CCL11. To confirm that FGF2 suppressed CCL11 expression in SDP11 cells, cells were cultured in the presence of FGF2 for $72 \mathrm{~h}$. The expression of 


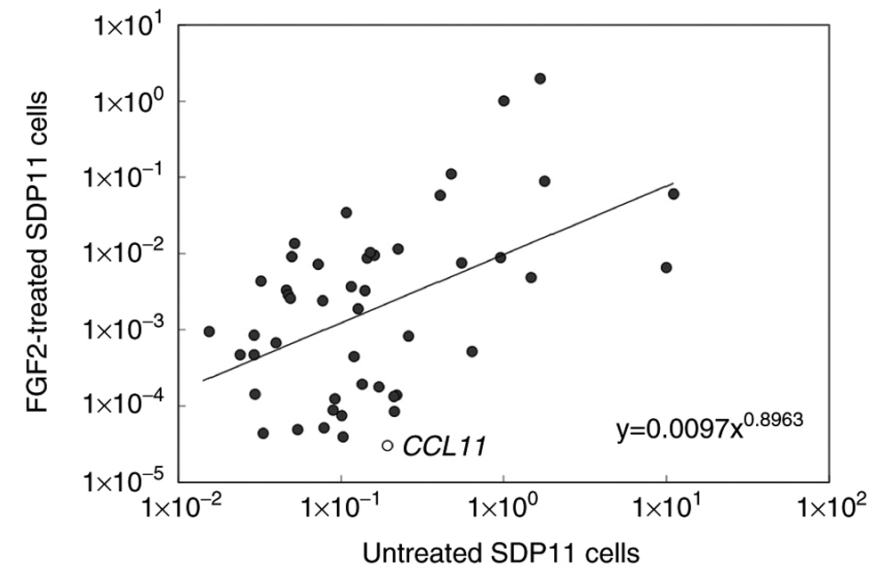

Figure 1. Expression of cytokine mRNA in SDP11 cells after treatment with FGF2. The expression of cytokine genes in SDP11 cells treated with or without $20 \mathrm{ng} / \mathrm{ml}$ FGF2 for $48 \mathrm{~h}$ was screened using PrimerArray ${ }^{\circledR}$, including 88 cytokine genes and 8 housekeeping genes (Table I). The white dot indicates CCL11, the expression of which was most suppressed by FGF2. FGF2, fibroblast growth factor 2; CCL11, C-C motif ligand 11.

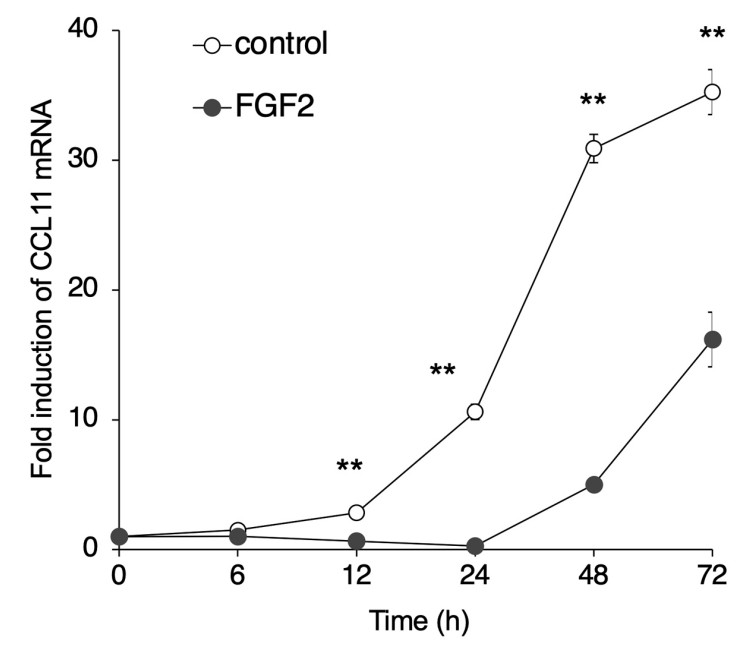

Figure 2. Time-dependent effects of FGF2 on the suppression of CCL11 expression. SDP11 cells were cultured with or without $20 \mathrm{ng} / \mathrm{ml} \mathrm{FGF2,} \mathrm{after}$ which the expression of CCL11 was analyzed by reverse transcription-quantitative PCR. The expression of CCL11 was significantly suppressed after $12 \mathrm{~h}$. Data are presented as the mean \pm SEM. ${ }^{* *} \mathrm{P}<0.01$ vs. control. FGF2, fibroblast growth factor 2; CCL11, C-C motif ligand 11.

CCL11 was then examined using RT-qPCR. CCL11 expression level decreased in cells following treatment with FGF2 for 12, 24, 48 and $72 \mathrm{~h}$ compared with untreated control cells (Fig. 2). Subsequently, the effect of FGF2 concentration on the expression of CCL11 was examined. To this end, SDP11 cells were cultured with $0.1,1,10,20$ and $40 \mathrm{ng} / \mathrm{ml} \mathrm{FGF2} \mathrm{for} 24 \mathrm{~h}$. The administration of $\geq 10 \mathrm{ng} / \mathrm{ml}$ FGF2 suppressed the expression of CCL11 compared with that in the control (Fig. 3). There were no significant differences at 0.1 and $1 \mathrm{ng} / \mathrm{ml} \mathrm{FGF2} \mathrm{(Fig.} \mathrm{3).}$ These results suggested that FGF2 negatively regulated the expression of CCL11 in dental pulp-derived MSCs in a timeand dose-dependent manner.

Regulation of expression of CCL11 by FGFR signaling. The subsequent aim of the present study was to characterize the

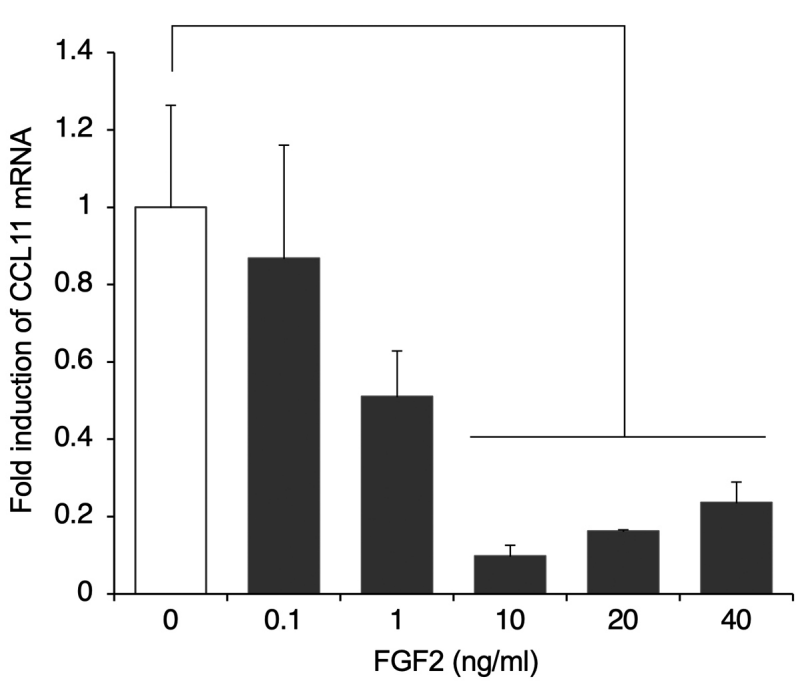

Figure 3. Dose-dependent effects of FGF2 on the suppression of the expression of CCL11. The expression of CCL11 was determined by reverse transcription-quantitative PCR in SDP11 cells treated with $0-40 \mathrm{ng} / \mathrm{ml}$ FGF2 for $24 \mathrm{~h}$. Administration of $>10 \mathrm{ng} / \mathrm{ml}$ FGF2 significantly suppressed the expression of CCL11. Data are presented as the mean \pm SEM. ${ }^{*} \mathrm{P}<0.05$. FGF2, fibroblast growth factor 2; CCL11, C-C motif ligand 11.

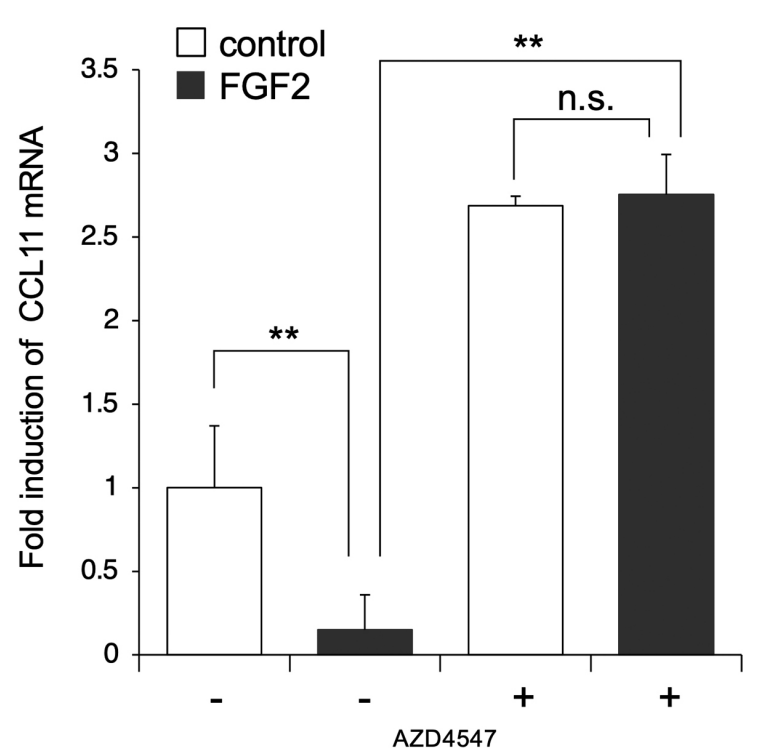

Figure 4. The AZD4547 FGFR inhibitor abolishes the suppression in the expression of CCL11. SDP11 cells were cultured in the presence of $10 \mu \mathrm{M}$ AZD4547 with or without $20 \mathrm{ng} / \mathrm{ml} \mathrm{FGF2} \mathrm{for} 24 \mathrm{~h}$, and the expression of CCL11 was analyzed by reverse transcription-quantitative PCR. AZD4547 attenuated the FGF2-mediated suppression of CCL11 expression. Data are presented as the mean \pm SEM. ${ }^{* *} \mathrm{P}<0.01$. FGFR, FGF receptor; FGF2, fibroblast growth factor 2; CCL11, C-C motif ligand 11; n.s., not significant.

effect of FGF2 on the suppression of CCL11 expression. To assess whether the FGF2-induced suppression of CCL11 was mediated by FGF receptor signaling, AZD4547, a selective FGFR1/2/3 inhibitor, was used in cell culture. SDP11 cells were cultured in the presence or absence of $20 \mathrm{ng} / \mathrm{ml} \mathrm{FGF} 2$ and with or without $10 \mu \mathrm{M}$ AZD4547 for $24 \mathrm{~h}$. The expression of CCL11 was then examined by RT-qPCR. The results indicated that AZD4547 abolished the FGF2-induced suppression of CCL11 (Fig. 4). Furthermore, the results demonstrated that 
A

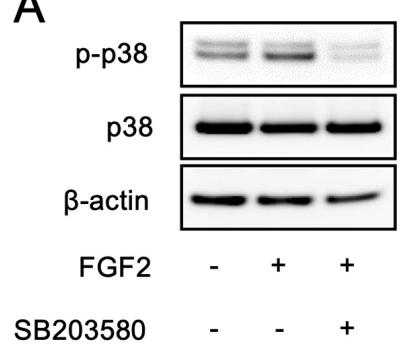

B

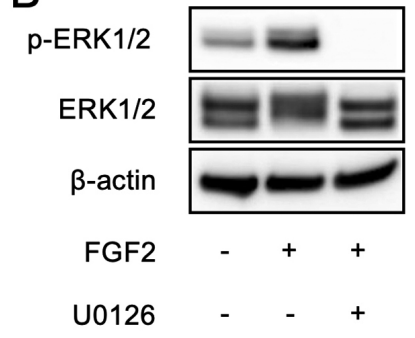

C

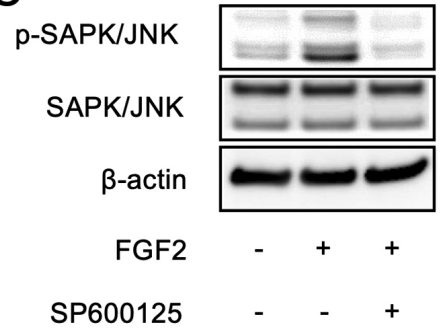

D

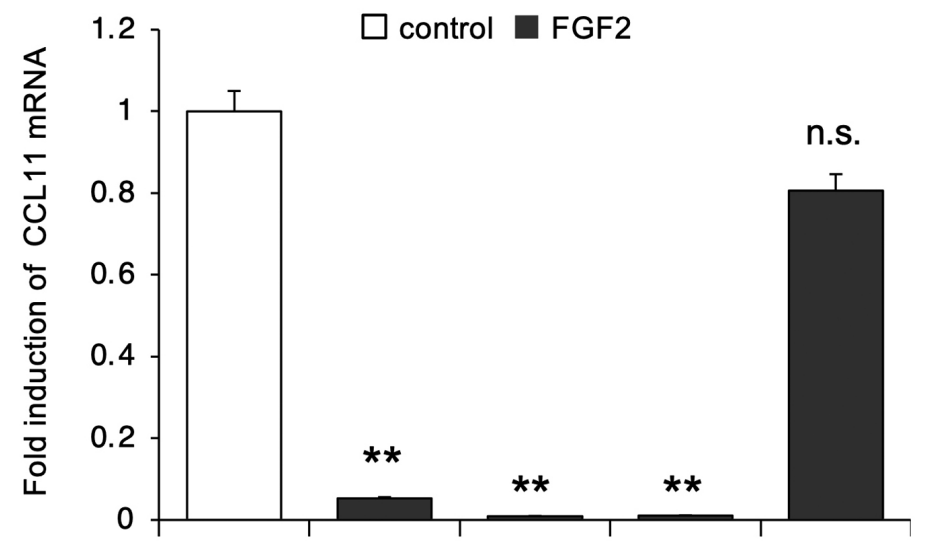

Inhibitor

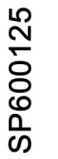

Figure 5. Phosphorylation levels of p38 MAPK, ERK1/2 and SAPK/JNK after treatment of SDP11 cells with FGF2. SDP11 cells were treated with FGF2 for 5 min, after which they were immunoblotted with (A) anti-p-p38 MAPK and anti-p38 MAPK, (B) anti-p-ERK1/2 and anti-ERK1/2, and (C) anti-p-SAPK/ JNK and anti-SAPK/JNK. Anti- $\beta$-actin antibodies were used for normalization. The effect of each specific kinase inhibitor, namely, p38 MAPK inhibitor (SB203580), MEK inhibitor (U0126) and JNK inhibitor (SP600125) was evaluated. FGF2 induced the phosphorylation of p38 MAPK, ERK1/2 and SAPK/ JNK, which was blocked by each respective inhibitor when co-administered. (D) SDP11 cells were cultured with or without 20 ng/ml FGF2 in the presence of $10 \mu \mathrm{M}$ SB203580, $10 \mu \mathrm{M}$ U0126 or SP600125 for $24 \mathrm{~h}$. The expression of CCL11 was then examined by reverse transcription-quantitative PCR. Only the JNK inhibitor blocked the FGF2-mediated suppression in the expression of CCL11. Data are presented as the mean $\pm \mathrm{SEM}$. ${ }^{* *} \mathrm{P}<0.01$. SAPK, stress-activated protein kinases; FGF2, fibroblast growth factor 2; CCL11, C-C motif ligand 11; n.s., not significant

AZD4547 increased the expression of CCL11 in the absence of exogenous administration of FGF2, which may have been due to the suppression of endogenous FGF signaling (Fig. 4). These results suggested that FGFR-mediated signaling played an important role in the regulation of the expression of CCL11 in dental pulp-derived MSCs.

FGF2 mediates the suppression of CCL11 via JNK signaling. To identify the signaling pathways involved in the FGF2-mediated suppression of CCL11 expression in SDP11 cells, western blotting was performed to examine the phosphorylation of p38 MAPK, ERK1/2 and JNK, which are different members of the MAP kinase family activated downstream of FGFR. The results indicated that FGF2 stimulated the phosphorylation of p38 MAPK, ERK1/2 and SAPK/JNK in SDP11 cells, which was suppressed following treatment with each specific kinase inhibitor, namely, the p38 MAPK (SB203580), MEK (U0126) and JNK (SP600125) inhibitors (Fig. 5A-C), respectively. To further clarify the pathway mediating the suppression of CCL11 expression downstream of FGF2, the levels of CCL11 were examined in cells cultured with FGF2 in the presence of each specific kinase inhibitor. The results indicated that SP600125, but not SB203580 or
U0126, inhibited the FGF2-induced suppression in the expression of CCL11 (Fig. 5D). The present results suggested that the JNK pathway was responsible for the inhibitory effect on the expression of CCL11 in human dental pulp-derived MSCs.

\section{Discussion}

The present study used an RT-qPCR-based primer array technique to analyze the FGF2-induced altered expression of cytokines in the SDP11 human dental pulp-derived MSC line. The results indicated that FGF2 regulated the expression of inflammatory cytokines in SDP11 cells, suggesting that FGF2 was involved in the regulation of inflammatory cytokines in pulp-derived MSCs. Furthermore, the expression level of CCL11 was significantly decreased by FGF2 in a time- and dose-dependent manner, and its inhibition was blocked by the AZD4547 FGFR inhibitor. The present study also reported that SP600125, an inhibitor of JNK, abolished the FGF2-induced suppression of CCL11. The current results suggested that FGF2 modulated the expression of CCL11 via the FGFR-JNK cascade in human dental pulp-derived MSCs.

Of note, FGF2 is known to play an important role in tooth development and dentin repair. The local application of 
gelatin hydrogel-delivered FGF2 to the exposed pulps of teeth with dentin defects was reported to induce the formation of dentin-like particles in vivo (30). Exogenous FGF2 was also shown to promote the activity of alkaline phosphatase, the formation of calcified nodules and the expression of odontogenic marker genes in human DPCs in vitro, suggesting that FGF2 positively regulated odontoblast differentiation (31). In contrast, it has also been reported that FGF2 inhibited the terminal differentiation of odontoblasts in pulp cells (32). Our preliminary study suggested that FGF2 is not involved in the formation of calcified nodules in SDP11 cells (data not shown). A previous study reported that continuous stimulation with FGF2 inhibited odontoblast differentiation, whereas early and limited stimulation with FGF2 markedly increased odontoblast differentiation in pulp cells (33). Similarly, FGF2-deficient mice were characterized by decreased osteoblast differentiation (17), while non-specific overexpression of FGF2 in transgenic mice under a phosphoglycerate kinase promoter lead to skeletal abnormalities, including shortening and flattening of long bones and moderate macrocephaly (34), indicating that FGF2 could act both as a positive and negative regulator of osteogenesis. Thus, the effect of FGF2 on odontoblast differentiation appears to be specific to the cell differentiation stage.

Another important property of FGF2 is its role in inflammation. In particular, FGF2 was found to prevent the neuroinflammation-induced decrease in the phosphorylation of ERK1/2 and alleviated the neuroinflammation-induced impairment in hippocampal neurogenesis (35). In another study, FGF2 improved the survival rate of septic mice by inhibiting the inflammatory response, alleviating lung injury (36). Moreover, FGF2 was reported to stimulate the migration and proliferation of endothelial cells in vivo and to relieve inflammation by inducing the expression of inflammation-related genes, such as proinflammatory cytokines and chemokines in endothelial cells (36-38). In human DPCs, FGF2 was demonstrated to induce the expression of chemokines, such as IL-6, IL-8, monocyte chemoattractant protein-1 $\alpha$ (MIP-1 $\alpha$ ) and MIP-3 $\alpha$ (31). These observations suggested that the pluripotent growth factor FGF2 efficiently directed cell populations toward the maintenance of tissue homeostasis and regeneration, depending on the inflammatory state. The present study also reported that FGF2 altered the cytokine expression profile of the SDP11 human dental pulp-derived MSC cell line. Interestingly, there have been numerous studies indicating that the expression of cytokines was increased by FGF2 $(31,39,40)$, whereas only a few studies have reported a decrease (31). Therefore, considering the multifunctionality of FGF2, the present study subsequently focused on the cytokines that were decreased following FGF2 treatment. The expression of CCL11 was found to be suppressed by exogenous FGF2 in SDP11 cells. The present results suggested that FGF2 negatively regulated the expression of CCL11 in human dental pulp-derived MSCs.

CCL11, a chemoattractant cytokine, is known to affect the cellular response to inflammatory conditions (19). CCL11 has also been indicated to correlate with aging and negative regulation of neurogenesis $(22,24)$. More specifically, CCL11 has been associated with chronic inflammation and the attenuation of nerve regeneration in old age (41). These results suggested that CCL11 and CCL11 receptors, such as CCR3, could serve as targets for anti-inflammatory therapies. In fact, ASM8, an antisense nucleotide targeting CCR3, was reported to enable a consistent protective effect against allergen-induced asthmatic responses (42). R321, another peptide-based CCR3 antagonist, which targets the second transmembrane helix and first extracellular loop of both human and mouse CCR3, has been suggested to be effective in the treatment of eosinophilic inflammation (43). Moreover, the administration of a CCL11-neutralizing antibody was indicated to induce tooth pulp regeneration by reducing the number of M1 macrophages and improving the M1/M2 ratio (44). M1 macrophages are typically activated during inflammation, whereas M2 macrophages are activated during anti-inflammatory responses and tissue regeneration (45). Accordingly, the present in vitro results suggested that the FGF2-mediated downregulation of CCL11 expression in dental MSCs had anti-inflammatory and tissue regeneration effects. Consistently, FGF was reported to be increased in reversible pulpitis but decreased in irreversible pulpitis, which significantly increased the expression of CCL11 (46).

FGF2 was reported to interact with specific cell surface receptors, including FGFR1, FGFR2, FGFR3 and FGFR4 (47). Accordingly, FGF2 signaling plays important roles in a multitude of physiological and pathological processes by regulating cell proliferation, migration, differentiation and survival (47). In addition, FGFR is a family of tyrosine kinases that can activate signaling cascades, such as RAS-MAPK, PI3K-AKT, phospholipase $\mathrm{C} \gamma$ and STAT (48). Among the downstream mediators of FGF2 signaling pathways, the MAPK pathway has been demonstrated to play a pivotal role in the function of stem cells, including mesenchymal stem cells (49-51). Thus, the present study focused on the MAPK pathway and found that FGF2 induced the phosphorylation of p38 MAPK, ERK1/2 and JNK in SDP11 cells. Likewise, in a previous study, treatment with FGF2, limited to the early stages of undifferentiated DPCs, promoted the formation of functional odontoblasts via the FGFR/MEK/ERK and bone morphogenetic protein signaling pathways (33). Moreover, ERK and p38 MAPK were found to induce the expression of osteogenic marker genes and promote osteoblast differentiation (52). The present study indicated that AZD4547 and SP600125, but not SB203580 or U0126, inhibited the FGF2-induced suppression of CCL11 in SDP11 cells. The present results suggested that the FGF2/FGFR/JNK pathway is involved in the FGF2-mediated suppression of the expression of CCL11 in human dental pulp-derived MSCs.

The present study demonstrated that FGF2 regulated the expression of cytokines in SDP11 cells and to the best of our knowledge, indicated for the first time that FGF2 may play a role in the suppression of the expression of CCL11 through the FGF2/FGFR/JNK signaling pathway. There are several limitations in the present study, mainly due to the use of a cell line as a mimic of human dental pulp-derived MSCs. However, analysis using a simple model is essential for clarifying the function of FGF2, as FGF2 contributes to tissue homeostasis and regeneration by recognizing its surrounding spatiotemporal environment and cross-talking with various cells, cytokines and signaling molecules (31). Further studies using primary cell cultures or in vivo models are required to confirm the results obtained in the present study. Finally, the 
present findings on the FGF2-mediated suppression of the expression of CCL11 could facilitate the delineation of the molecular mechanisms of tissue regeneration in teeth.

\section{Acknowledgements}

Not applicable.

\section{Funding}

The present work was supported by JSPS KAKENHI (grant nos. 17H04414, 20H03898, 17K17332, 20K10205, 20K18760 and $16 \mathrm{~K} 11804)$.

\section{Availability of data and materials}

The datasets used and/or analyzed during the current study are available from the corresponding author on reasonable request.

\section{Authors' contributions}

TH and TIwam conceived and designed the study. RK, YA, TK and TH participated in patient recruitment and preparation of primary cells. RK, TH, KI, AS, KYU, AM, AN, KK and $\mathrm{HN}$ carried out the molecular analyses and interpreted the data. RK, TH, TIwas and TIwam carried out the data analyses. TH, YA, RK, and TIwam confirm the authenticity of all the raw data. TIwam and RK wrote the manuscript. All authors read and approved the manuscript.

\section{Ethics approval and consent to participate}

Ethical approval was obtained from the Ethics Committee of Tokushima University Hospital (approval no. 1799). Written informed consent was obtained from all patients or their guardians, based on the guidelines set by the Ethics Committee of Tokushima University Hospital (Tokushima, Japan).

\section{Patient consent for publication}

Not applicable.

\section{Competing interests}

The authors declare that they have no competing interests.

\section{References}

1. Friedenstein AJ, Chailakhjan RK and Lalykina KS: The development of fibroblast colonies in monolayer cultures of guinea-pig bone marrow and spleen cells. Cell Tissue Kinet 3: 393-403, 1970.

2. Williams JT, Southerland SS, Souza J, Calcutt AF and Cartledge RG: Cells isolated from adult human skeletal muscle capable of differentiating into multiple mesodermal phenotypes. Am Surg 65: 22-26, 1999.

3. Toma JG, Akhavan M, Fernandes KJ, Barnabé-Heider F, Sadikot A, Kaplan DR and Miller FD: Isolation of multipotent adult stem cells from the dermis of mammalian skin. Nat Cell Biol 3: 778-784, 2001

4. Zuk PA, Zhu M, Mizuno H, Huang J, Futrell JW, Katz AJ, Benhaim P, Lorenz HP and Hedrick MH: Multilineage cells from human adipose tissue: Implications for cell-based therapies. Tissue Eng 7: 211-228, 2001.
5. Erices A, Conget $\mathrm{P}$ and Minguell JJ: Mesenchymal progenitor cells in human umbilical cord blood. Br J Haematol 109: 235-242, 2000.

6. Gronthos S, Mankani M, Brahim J, Robey PG and Shi S: Postnatal human dental pulp stem cells (DPSCs) in vitro and in vivo. Proc Natl Acad Sci USA 97: 13625-13630, 2000

7. Seo BM, Miura M, Gronthos S, Bartold PM, Batouli S, Brahim J, Young M, Robey PG, Wang CY and Shi S: Investigation of multipotent postnatal stem cells from human periodontal ligament. Lancet 364: 149-155, 2004.

8. Miura M, Gronthos S, Zhao M, Lu B, Fisher LW, Robey PG and Shi S: SHED: Stem cells from human exfoliated deciduous teeth. Proc Natl Acad Sci USA 100: 5807-5812, 2003.

9. Ferraro F, Celso CL and Scadden D: Adult stem cels and their niches. Adv Exp Med Biol 695: 155-168, 2010.

10. Cheung AS, Zhang DK, Koshy ST and Mooney DJ: Scaffolds that mimic antigen-presenting cells enable ex vivo expansion of primary T cells. Nat Biotechnol 36: 160-169, 2018.

11. Padma AM, Carrière L, Krokström Karlsson F, Sehic E, Bandstein S, Tiemann TT, Oltean M, Song MJ, Brännström M and Hellström M: Towards a bioengineered uterus: Bioactive sheep uterus scaffolds are effectively recellularized by enzymatic preconditioning. NPJ Regen Med 6: 26, 2021.

12. Martin I, Galipeau J, Kessler C, Le Blanc K and Dazzi F: Challenges for mesenchymal stromal cell therapies. Sci Transl Med 11: 11, 2019.

13. Galipeau J and Sensébé L: Mesenchymal stromal cells: Clinical challenges and therapeutic opportunities. Cell Stem Cell 22: 824-833, 2018.

14. Guillonneau X, Tassin J, Berrou E, Bryckaert M, Courtois Y and Mascarelli F: In vitro changes in plasma membrane heparan sulfate proteoglycans and in perlecan expression participate in the regulation of fibroblast growth factor 2 mitogenic activity. J Cell Physiol 166: 170-187, 1996.

15. Brewer JR, Mazot P and Soriano P: Genetic insights into the mechanisms of Fgf signaling. Genes Dev 30: 751-771, 2016.

16. Ortega S, Ittmann M, Tsang SH, Ehrlich M and Basilico C: Neuronal defects and delayed wound healing in mice lacking fibroblast growth factor 2. Proc Natl Acad Sci USA 95: 5672-5677, 1998.

17. Montero A, Okada Y, Tomita M,Ito M, Tsurukami H,Nakamura T, Doetschman T, Coffin JD and Hurley MM: Disruption of the fibroblast growth factor-2 gene results in decreased bone mass and bone formation. J Clin Invest 105: 1085-1093, 2000.

18. Lou ZC and Wang YB: Healing outcomes of large $(>50 \%)$ traumatic membrane perforations with inverted edges following no intervention, edge approximation and fibroblast growth factor application; a sequential allocation, three-armed trial. Clin Otolaryngol 38: 289-296, 2013.

19. Mattoli S, Stacey MA, Sun G, Bellini A and Marini M: Eotaxin expression and eosinophilic inflammation in asthma. Biochem Biophys Res Commun 236: 299-301, 1997.

20. Kitaura M, Nakajima T, Imai T, Harada S, Combadiere C, Tiffany HL, Murphy PM and Yoshie O: Molecular cloning of human eotaxin, an eosinophil-selective CC chemokine, and identification of a specific eosinophil eotaxin receptor, $\mathrm{CC}$ chemokine receptor 3. J Biol Chem 271: 7725-7730, 1996.

21. Ogilvie P, Bardi G, Clark-Lewis I, Baggiolini M and Uguccioni M: Eotaxin is a natural antagonist for CCR2 and an agonist for CCR5. Blood 97: 1920-1924, 2001.

22. Villeda SA, Luo J, Mosher KI, Zou B, Britschgi M, Bieri G, Stan TM, Fainberg N, Ding Z, Eggel A, et al: The ageing systemic milieu negatively regulates neurogenesis and cognitive function. Nature 477: 90-94, 2011.

23. Czepielewski LS, Massuda R, Panizzutti B, Grun LK, Barbé-Tuana FM, Teixeira AL, Barch DM and Gama CS: Telomere length and CCL11 levels are associated with gray matter volume and episodic memory performance in schizophrenia: Evidence of pathological accelerated aging. Schizophr Bull 44: 158-167, 2018.

24. Huber AK, Giles DA, Segal BM and Irani DN: An emerging role for eotaxins in neurodegenerative disease. Clin Immunol 189: 29-33, 2018.

25. Wang W, Huang CY, Wang ZP, Xu SS, Qian TY, Chen YD and Wu WG: Serum C-C motif ligand 11/eotaxin-1 may serve as a candidate biomarker for postmenopausal osteoporosis. J Med Biochem 38: 353-360, 2019.

26. Kindstedt E, Holm CK, Sulniute R, Martinez-Carrasco I, Lundmark R and Lundberg P: CCL11, a novel mediator of inflammatory bone resorption. Sci Rep 7: 5334, 2017. 
27. Akazawa Y, Hasegawa T, Yoshimura Y, Chosa N, Asakawa T, Ueda K, Sugimoto A, Kitamura T, Nakagawa H, Ishisaki A, et al: Recruitment of mesenchymal stem cells by stromal cell-derived factor $1 \alpha$ in pulp cells from deciduous teeth. Int J Mol Med 36 : 442-448, 2015

28. Iwamoto T, Nakamura T, Ishikawa M, Yoshizaki K, Sugimoto A, Ida-Yonemochi $\mathrm{H}$, Ohshima $\mathrm{H}$, Saito $\mathrm{M}$, Yamada $\mathrm{Y}$ and Fukumoto S: Pannexin 3 regulates proliferation and differentiation of odontoblasts via its hemichannel activities. PLoS One 12: e0177557, 2017

29. Livak KJ and Schmittgen TD: Analysis of relative gene expression data using real-time quantitative PCR and the 2(-Delta Delta C(T)) method. Methods 25: 402-408, 2001.

30. Kikuchi N, Kitamura C, Morotomi T, Inuyama Y, Ishimatsu H, Tabata Y, Nishihara T and Terashita M: Formation of dentin-like particles in dentin defects above exposed pulp by controlled release of fibroblast growth factor 2 from gelatin hydrogels. J Endod 33: 1198-1202, 2007.

31. Kim YS, Min KS, Jeong DH, Jang JH, Kim HW and Kim EC: Effects of fibroblast growth factor- 2 on the expression and regulation of chemokines in human dental pulp cells. J Endod 36: 1824-1830, 2010

32. Sagomonyants K, Kalajzic I, Maye P and Mina M: FGF signaling prevents the terminal differentiation of odontoblasts. J Dent Res 96: 663-670, 2017.

33. Sagomonyants K, Kalajzic I, Maye P and Mina M: Enhanced dentinogenesis of pulp progenitors by early exposure to FGF2. J Dent Res 94: 1582-1590, 2015.

34. Coffin JD, Florkiewicz RZ, Neumann J, Mort-Hopkins T, Dorn GW II, Lightfoot P, German R, Howles PN, Kier A and O'Toole BA: Abnormal bone growth and selective translational regulation in basic fibroblast growth factor (FGF-2) transgenic mice. Mol Biol Cell 6: 1861-1873, 1995.

35. Tang MM, Lin WJ, Zhang JT, Zhao YW and Li YC: Exogenous FGF2 reverses depressive-like behaviors and restores the suppressed FGF2-ERK1/2 signaling and the impaired hippocampal neurogenesis induced by neuroinflammation. Brain Behav Immun 66: 322-331, 2017

36. Pan X, Xu S, Zhou Z, Wang F, Mao L, Li H, Wu C, Wang J, Huang Y, Li D, et al: Fibroblast growth factor-2 alleviates the capillary leakage and inflammation in sepsis. Mol Med 26: 108, 2020.

37. Garmy-Susini B, Delmas E, Gourdy P, Zhou M, Bossard C, Bugler B, Bayard F, Krust A, Prats AC, Doetschman T, et al: Role of fibroblast growth factor-2 isoforms in the effect of estradiol on endothelial cell migration and proliferation. Circ Res 94: 1301-1309, 2004

38. Presta M, Andrés G, Leali D, Dell'Era P and Ronca R: Inflammatory cells and chemokines sustain FGF2-induced angiogenesis. Eur Cytokine Netw 20: 39-50, 2009.

39. Gronthos S, Brahim J, Li W, Fisher LW, Cherman N, Boyde A, DenBesten P, Robey PG and Shi S: Stem cell properties of human dental pulp stem cells. J Dent Res 81: 531-535, 2002.

40. Vaseenon S, Chattipakorn N and Chattipakorn SC: The possible role of basic fibroblast growth factor in dental pulp. Arch Oral Biol 109: 104574, 2020
41. Büttner R, Schulz A, Reuter M, Akula AK, Mindos T, Carlstedt A, Riecken LB, Baader SL, Bauer R and Morrison H: Inflammaging impairs peripheral nerve maintenance and regeneration. Aging Cell 17: e12833, 2018

42. Gauvreau GM, Boulet LP, Cockcroft DW, Baatjes A, Cote J, Deschesnes F, Davis B, Strinich T, Howie K, Duong M, et al: Antisense therapy against CCR3 and the common beta chain attenuates allergen-induced eosinophilic responses. Am J Respir Crit Care Med 177: 952-958, 2008.

43. Pease JE and Williams TJ: Tipping the balance: A biased nanobody antagonist of CCR3 with potential for the treatment of eosinophilic inflammation. J Allergy Clin Immunol 143: 552-553, 2019

44. Hayashi Y, Kawamura R, Nishimatsu SI, Fukuta O and Nakashima M: Stem cell-induced pulp regeneration can be enhanced by administration of CCL11-neutralizing antibody in the ectopic tooth transplantation model in the aged mice. Rejuvenation Res 22: 51-59, 2019.

45. Mills CD, Kincaid K, Alt JM, Heilman MJ and Hill AM: M-1/M-2 macrophages and the Th1/Th2 paradigm. J Immunol 164: 6166-6173, 2000.

46. Abd-Elmeguid A, Abdeldayem M, Kline LW, Moqbel R, Vliagoftis $\mathrm{H}$ and $\mathrm{Yu}$ DC: Osteocalcin expression in pulp inflammation. J Endod 39: 865-872, 2013.

47. Bikfalvi A, Klein S, Pintucci G and Rifkin DB: Biological roles of fibroblast growth factor-2. Endocr Rev 18: 26-45, 1997.

48. Powers CJ, McLeskey SW and Wellstein A: Fibroblast growth factors, their receptors and signaling. Endocr Relat Cancer 7: 165-197, 2000.

49. Kunath T, Saba-El-Leil MK, Almousailleakh M, Wray J, Meloche $S$ and Smith A: FGF stimulation of the Erk1/2 signalling cascade triggers transition of pluripotent embryonic stem cells from self-renewal to lineage commitment. Development 134: 2895-2902, 2007.

50. Haghighi F, Dahlmann J, Nakhaei-Rad S, Lang A, Kutschka I, Zenker M, Kensah G, Piekorz RP and Ahmadian MR: bFGF-mediated pluripotency maintenance in human induced pluripotent stem cells is associated with NRAS-MAPK signaling. Cell Commun Signal 16: 96, 2018.

51. Ma Y, Kakudo N, Morimoto N, Lai F, Taketani S and Kusumoto K: Fibroblast growth factor-2 stimulates proliferation of human adipose-derived stem cells via Src activation. Stem Cell Res Ther 10: 350, 2019.

52. Franceschi RT and Ge C: Control of the Osteoblast Lineage by Mitogen-Activated Protein Kinase Signaling. Curr Mol Biol Rep 3: 122-132, 2017.

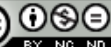

This work is licensed under a Creative Commons Attribution-NonCommercial-NoDerivatives 4.0 International (CC BY-NC-ND 4.0) License. 